\title{
Essential Drug Stock Alert Tracker in Provincial Department of Health Services Western Province
}

\section{Ranwala R A D L M K, Nanayakkara N K V, Sheriff M R}

${ }^{1}$ Regional Director of Health Services Office, Colombo, ${ }^{2}$ Provincial Department of Health Services, Western Province, ${ }^{3}$ National Institute of Mental Health, Sri Lanka

\section{Key words: Drug information System}

Introduction
The health indices in Sri Lanka is well above the regional health indices, which can be partly
attributed to the free health care system. However, lack of pharmacy supplies in government
health institutions, especially in divisional hospitals, is a major complaint from the general public.
Health care institutions under the purview of Provincial Director of Health Services (PDHS)
receive pharmacy items from the Regional Medical Supplies Division (RMSD). Some of the
reasons for shortage of pharmacy items are poor communication between RMSD and health
institutions, mal-distribution of items at RMSD and actual drug shortage. Currently there is no
manual or electronic mechanism to monitor the "institution's essential drugs status" at any level,
resulting in difficulty to replenish stocks in a timely manner.
Objective
The objective of this system is to alert the health care institutional heads and regional/provincial
administrators about essential drug status and to effectively mobilize the available drugs.
Methods
A Web based system was designed with a simple data entry format and color code system. A
dashboard facilitates the visualization of the available stock with green (satisfactory), yellow
(reorder), red (zero stock). User levels in the system include institution, RMSD, Regional and
Provincial levels. Currently 26 essential drug items are monitored by the system.
Results
Before implementing the system, there were 38 occasions (11.73\%) of zero stock level for any of
the 26 essential drugs in Divisional hospitals. In 66 occasions (20.37\%) the drugs were at low
stock level. This has improved to $1.54 \%$ and $8.02 \%$ respectively as at April 2016.
Conclusion
While more evidence is needed it can be initially concluded that an online, real-time,
transparent, and easy to use drug alert system has shown benefit in the availability,
management, and avoidance of shortfall of drugs in the Western Province.
Corresponding Author: Ranwala RADLMK, Email: <lasantha13@gmail.com>
Presentation at the 5th biennial academic sessions of the Postgraduate institute of Medicine on 06
October 2016 Competing Interests: Authors have declared that no competing interests exist.

